\title{
Engaging Palm Oil and Hot Spot Area to Mitigate Forest Fires
}

\author{
Ariesta Lestari $^{1,2}$, Katriani Puspita Ayu ${ }^{1,3^{*}}$ \\ ${ }^{1}$ Information Sy stem Technical Department, Palangkaraya University, Central Kalimantan, Indonesia \\ ${ }^{2}$ Ph.D Candidate, Monash University, Australia \\ ${ }^{3}$ Ph.D candidate, Leiden University, Netherlands
}

\begin{abstract}
Forest fire is one of environmental problem happens in Central Kalimantan. The fire does not only damage the forest ecosystem and biodiversity but also threaten the health and socio-economic of local people. Forest fire in Central Kalimantan is widely known as human-made, such as the process of shifting cultivation and land clearing. The expansion of forest into palm oil plantation is often blamed as the cause of forest fire since the forest clearing involves a massive amount of fires. Therefore, this study aims to explore whether the existence of palm oil cultivation contributes to the occurrence of forest fires. We used satellite imagery of hotspot, and overlay it with the land use data to generate the fire risk zone map using geographic information system (GIS) method. Through the map, the risk of fire can be monitored in advance to help the fire authority provide the act of mitigation. The result of this study suggested that risk mapping is vital for forest fire management to mitigate the spread of forest fire. The region to be fire-prone within the palm oil cultivation is suggested to form a preventive act through active forest-fires monitoring. In sum, this study is expected to provide a map of forest fires' risk around the cultivation area, mainly palm oil plantation, and help the fire authorities as well as stakeholders to identify the risk zone for fires prevention in the future.
\end{abstract}

\section{Introduction}

Forest and land fires are annual events that occur in various provinces in Indonesia. One of the provinces that experienced vast forest and land fires since the early 1990s is Central Kalimantan. World Resources Institute [1] claims, between 1985 and 1997 were the periods of forest loss nearly 10 million hectares in Kalimantan. The drought of El Nino in 1997-1998 was the initial event, and the beginning of uncontrol forest fire and people gained momentum in land clearing [2]. As a result, the province faces the increased rates of deforestation from the excessive chop-down of trees and utilizes fires to clear up the forest area into plantation [3]. The condition of forest fires in Central Kalimantan has to elevate annual haze and smoke disaster for the last three decades. It has been causing a severe environmental problem in Central Kalimantan and damaging the source of local livelihood. Moreover, despite the anti-fire regional policy for forest clearance, the ecological degradation, and smoke disaster remains to threaten the forests and peatland underneath.

The annual forest fires trigger hotspots in the area of deep peat and cause fire underneath the peatland. The condition in 2015 considered out of control in which risking human health and wealth. Forest fires are the human-made disaster and can be prevented. The prime step to protect the forest is to mitigate the fire spreading. Forest fire in Central Kalimantan is widely known caused by the process of shifting cultivation and land clearing. The expansion of forest into palm oil plantation is often pointed out as the cause of annual forest fire. Since the forest clearing for palm oil involves a massive amount of fires, after three decades, the hotspot gradually emerges in strategic places such as the deep peat area. Therefore, immediate action needs to be conducted in controlling the fire area or even preventing the prospectus area.

Geospatial technology provides the tools necessary to develop a forest fire susceptibility map to identify the hazard area. The accurate data on fire area or hotspot is essential to record the previous, current, and potential disaster. The management of data has a crucial role in preventing or reducing collateral damage to the fire area. It also gives valid information for the stakeholder to decide on handling the fire disaster. The data sharing among related institutions might support the fast response to fire and reduce the chance of prolonged smoke disaster. Therefore, accurate data and information must be able to be accessed by the regional and national governments. At least five crucial agencies that must be informed about the data of forest fires, namely: Forestry Agency, Estate Crop Agency, Environmental Agency, Regional Board Disaster Management and The Center of Climate Change, Forest and Land Fire Control.

The objective of this study is to develop and produce a forest fire disaster map on plantation areas to respond faster to the potential hazard in Central Kalimantan using geographic information systems (GIS). To produce a precise evaluation of forest fire problems and decide on solutions, this study will map fire disasters from 2010 to 2017 and overlay the palm oil area within the same timeframe to produce fire disaster zone mapping.

\subsection{Literature Review}

To explore whether the existence of palm oil cultivation contributes to the occurrence of forest fires, in-depth research on the palm oil cultivation area needs to conduct. First of all, actors in the forest and land use management need to identify along with the driver on the land-use change activity. Second, factors in the 
occurrence of fire in Central Kalimantan are vital to be determined. It is believed that the drainage of peatlands is the root cause of the annual fire crisis. The tropical peatlands of Kalimantan Central are one of the largest expanses of tropical rainforest in Asia, with the populations of the critically endangered orangutan amongst another rich biodiversity. The socio-economic activities on peatlands involve peat drainage through human-made canals in an attempt to clear the land for cultivation, habitation, or to transport timber from the forest to the processing points on rivers. The problem is that dry peat is highly flammable and potentially burn in the dry season, and fires are burning above the drained peatland as well as underground. According to the study by Gaveau et al. [4], they indicate that small or large companies may start fires. Despite the efficiencyeconomic reason for using fire, both companies are using fire to clear, open access to the land, and increase the value of the land. Among plantations in Central Kalimantan, the most significant portion belongs to the large companies; consequently, the main actor that often to be blamed is the palm oil significant corporation activities on peatland. They were claimed to be the actor in creating haze hazards. Although the effect of El Nino during dry season might contribute to the haze and smoke crisis in Central Kalimantan, large companies and their activity in opening land remain the cause of the annual disaster. Therefore, the history of forest fires needs to be analyses along with various other aspects.

In 1997-1998 Central Kalimantan experienced a fire episode and became the first severe fire in size and impact $[5,6]$. A prolonged and severe fire occurred during the ENSO of 1997-1998. The period of drought in 1997 was six months; despite the short rainy season, the fire remains happened in the following year. According to Goldammer [5], the fires of 1997-1998 were humancaused due to land large-scale forest conversion into land cultivation. He claimed that this situation happened as a result of inadequate and unenforced land-use policies. The absence of inter-agency coordination to respond and act in extinguish the fires was the major problem in the severity of the fire's disaster. Although fires in 1999 were not severe as those in 1997 and 1998, the risk of fires remains occurs along with the drought in the dry season. As predicted in 2001-2002, the fires remain the same old problem for Central Kalimantan.

To discover the location of forest fires disaster, the technology used is spatial information technology. Geographic information system (GIS) is a computerbased tool in which designed to capture, store, analyze, manage, and present geographical data for mapping and analyzing features and describing places on the earth's surface. For that reason, GIS is a location intelligence software that can be the foundation for many locationenabled services, i.e., the location of palm oil or forest fires because both of them rely on visualization on the earth's surface. GIS plays a role in capturing, storing, checking, and displaying data related to positions of palm oil and fires on the Central Kalimantan area. The software also helps government agencies to understand Central Kalimantan spatial patterns and its relation to the history of forest fires and smoke disaster. This software stores data in the database and then represent it visually in a mapped format; therefore, the history of spatial, forest burning, and smoke disaster becomes essential to determine the pattern of haze and smoke disaster in Central Kalimantan. The outcome is mapping as the central function of the Geographic Information System by providing a visual interpretation of data. The stakeholders use this map to understand the latest situation of fire or smoke hazard as well as to communicate the current situation as an act of disaster mitigation. The accessible map provides a visual representation of data to be used in decision making at every level of the government agency.

\section{Methods}

\subsection{Study Area}

The present study area is Central Kalimantan, which geographically located at 0.45 degrees North Latitude, 3.30 degrees South Latitude and 111 degrees East Longitude. The total area is $153,564 \mathrm{~km}^{2}$ or 15.426 .781 Ha. Central Kalimantan has 13 regencies and one city with Murung Raya as the largest regency reaching $23,700 \mathrm{~km}^{2}$ followed by Katingan $17,500 \mathrm{~km}^{2}$. Gunung Mas Regency has an area of $10,805 \mathrm{~km}^{2}$. The forest area is 12,7 million ha or 82,45 percent of the whole province. Across the province, the largest regencies with palm oil plantation are West Kotawaringin, East Kotawaringin, and Seruyan. The study area map is shown in Figure 1.

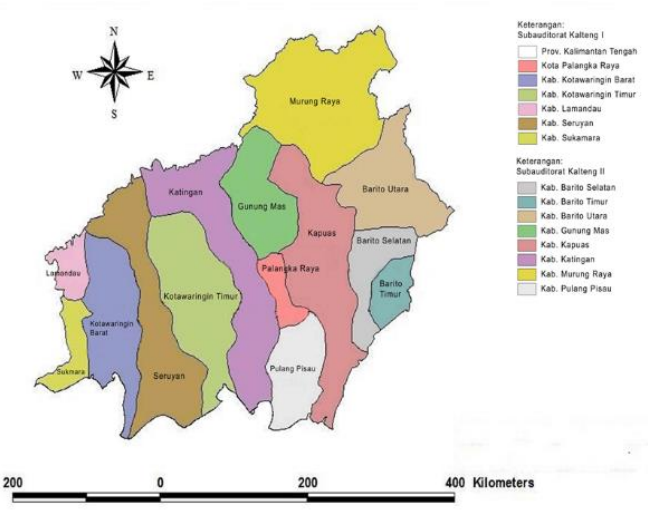

Figure 1. The Administration map of Central Kalimantan, Indonesia.

The land use in the study area is mainly for production forest, protected forest, and conservation forest. Based on Indonesia's Meteorological Services Department, the climate in Central Kalimantan from July to October is dry season and historically proved to be fragile for fires. The map below from BMKG shows that in September 2019, the area with potential fires is in Lamandau, West Kotawaringin, East Kotawaringin, and Seruyan. 


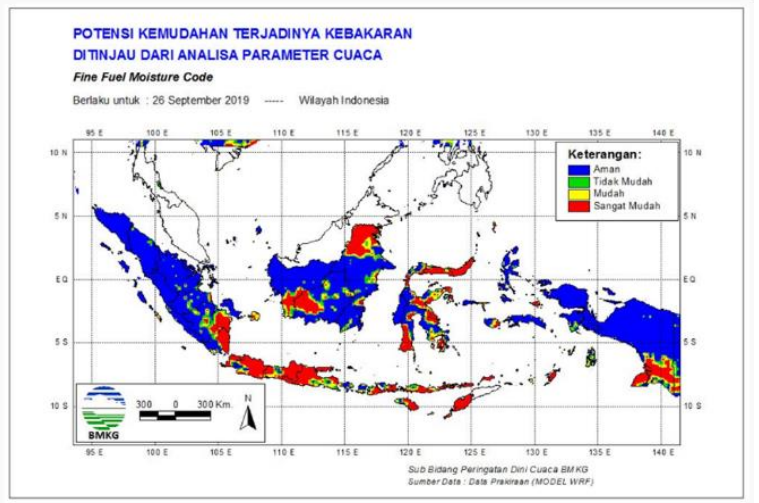

Figure 2. The potential of fires through climate parameter (Source: BMKG, 2019)

\subsection{Procedure}

This study provides an analysis of forest resource governance, including land and resource tenure, in Central Kalimantan, focusing in particular on the area of palm oil cultivation. The study takes a close look at cultivation rights within forests and the hotspot within the palm oil cultivation. The land use management and its relation to fire disaster might not explain more indepth; however, the immediate need is to map the fire risk in the plantation area. The reason for risk mapping is crucial because the tool of land clearing in Central Kalimantan is fire. The main gaps and challenges in forest management in Central Kalimantan emerging from this study relate to the act of smoke hazard prevention, access to act on extinguish the fire in cultivation area, responsibilities of concession on fire hazard, and coordination between relevant government agencies.

This study seeks a way to control the burning area and smoke hazard through risk maps. First of all, this paper has to understand the pattern of occurring and spreading fires. Second, the other factor that needs to be identified is the climate. The dry season from June to September is the time usually fire and smoke hazard appears. Therefore, it needs to be considered that the annual disaster happens within that timeframe. Third, this study used satellite imagery of hotspot and overlay it with the land use data to generate the fire risk zone map. It allows assessing whether the plantation area links to the fire or affected by the wind and peatland situation. The diagnosis of fire risk areas can contribute to mitigating processes intended for preventive purposes. Thus, an accurate pinpointing of the hotspot and the oil palm area are essential to studies the map and to prevent fires. Through the map, the risk of fire can be monitored in advance to help the fire authority provide the act of mitigation.

\subsection{Data}

The dependent variable, active fire occurrence from 2010 to 2018, was extracted from the database of active fires the NASA FIRMS Fire Archive, which is based on remote sensing data from Moderate Resolution Imaging Spectroradiometer (MODIS) satellite. Between 2010 and
2015, there are 83,608 hotspots or active fire found all over Central Kalimantan. As shown in Figure 3, in nine years, the hotspot occurrence reached a peak in the year 2015. The year 2015 was known as the severe El-Nino year, where the dry season occurred for more than three months. According to Pan et al. [7], "different degrees of drought and fire activities in Indonesia, are associated with distinct strengths and types of El Niño and phases of IOD." Field mentions that the Indonesian drought is more intensive and prolonged in the Eastern Pacific type of El Nino years. He founds that the fires in Indonesia are at least twice as intensive when the Indian Ocean Dipole (IOD) phenomena are positive, and such events are often associated with El Niño.

The link of fire activity in Indonesia with El Niño events also proved by Chen et al. [8]. He states that during 1997-2015, Eastern Pacific (EP) El Niño events, the most massive fire happened in Southern Kalimantan, for an instant in 1997, 2006, and 2015 fire events. He also mentions that Central Pacific (CP) El Niño events consistently produced minor fire events. The EP El Niño is found to be more capable than the CP El Niño in prolonging Kalimantan's drought condition from September to October.

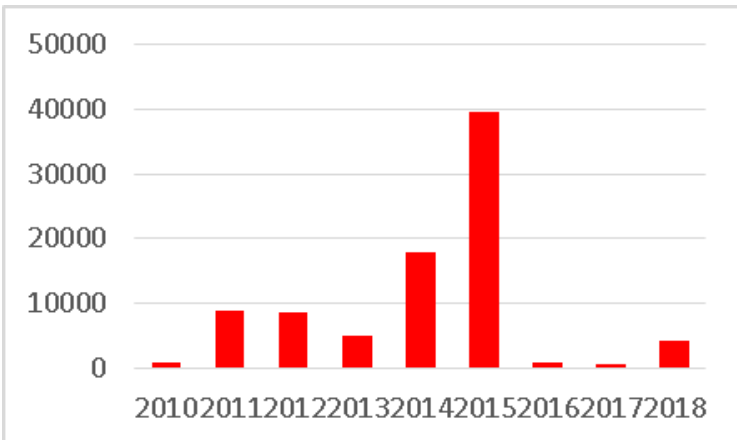

Figure 3. Hotspot Occurrence in Central Kalimantan from 2010-2018

This paper uses the data on land use of forest released by plantation agency, which categorizes as shown in Table 1.

Table 1. Land Use Category

\begin{tabular}{cll}
\hline NO & LAND USE TYPE & AREA (HA) \\
\hline $\mathbf{1}$ & APL & $3,984,058.56$ \\
$\mathbf{2}$ & Waterbody & $335,482.25$ \\
$\mathbf{3}$ & HL & $2,663,698.53$ \\
$\mathbf{4}$ & HP & $9,033,319.75$ \\
$\mathbf{5}$ & HPK & $3,644,698.24$ \\
$\mathbf{6}$ & HPKT & $16,177,039.71$ \\
$\mathbf{7}$ & Cons ervation Area & $22,541.95$ \\
$\mathbf{8}$ & KSA/KPA & $3,535,160.24$ \\
\hline
\end{tabular}

The hotspot data from satellite and land use are then overlaid with the Palm Oil Plantation map to investigate the relationship between the existence of palm oil plantation in the area with the occurrence of fire. Based on the database from the Plantation Agency of Central Kalimantan, there is 115 palm oil company that has an area of more than 1.4 million ha in total. 


\section{Results and Discussion}

In this research, we overlaid the palm oil plantation with the land use map from the Ministry of Forestry. The purpose of this method is to investigate whether palm oil was planted outside authority. The policy from the plantation agency of Central Kalimantan stated that palm oil companies should only exist in conversion production forest (Hutan Produksi Konversi/HPK), which is considered as the State Forest and not a Cultivation Rights (HGU). However, our study found that plenty of palm oil company opens their plantation trespassing HPK border. As shown in Figure 4, we take one sample of a palm oil company in the South Barito district, which sees the location of PT. BAS not only located inside HPK but also located in the HPT area. The permit of PT BAS was awarded in 2009 and strictly for the palm oil cultivation. The permit is inside the HPK area but also enters the area of production forest (HP), which by regulation, violates the land use permit. Besides, the area has a hotspot, which means that it suspected of fire usage within that concession area.

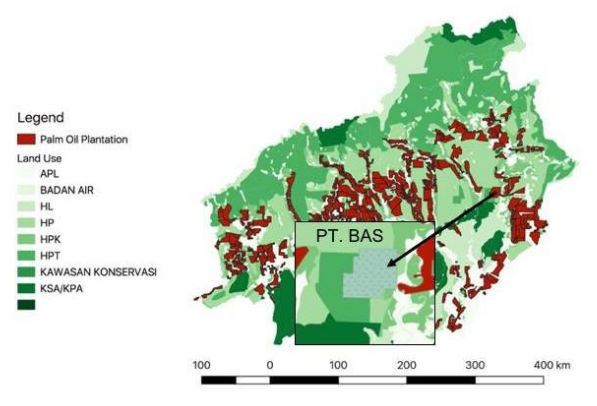

Figure 4. Location of palm oil plantation

The result from the overlaying process between hotspot occurrence in the area of Conversion Forest (HPK), Production forest, and other purpose lands (APL) shows that the location of Palm Oil Plantation covers with 18.654 hotspots or $22 \%$ of the hotspot occurred within the plantation area. Ramdani [9] stated that one of the causes of rainforest cover loss in Indonesia is the land clearing for oil palm, and the easiest way to clear the land is by using fires. Therefore, the Indonesian government accused palm oil companies of being responsible for lighting these fires to clear the land. The massive number of the hotspot in the palm oil plantation area indicates the massive contribution into the event of the fire. As shown in Figure 5, in 2015, almost all the area of palm oil plantation was detected with massive active fires.

Figure 6 shows that HP is the area that is more prone to fire, followed by HPK and APL, respectively. The result that shown HPK and APL are the second and third areas that prone to hotspot occurrence can be predictable. Since this area mostly used as palm oil plantation. It is common knowledge that the area of the plantation is more prone to fire, especially in the dry season. People tend to do a massive land clearing using fire to open the forest and turn it into the plantation.

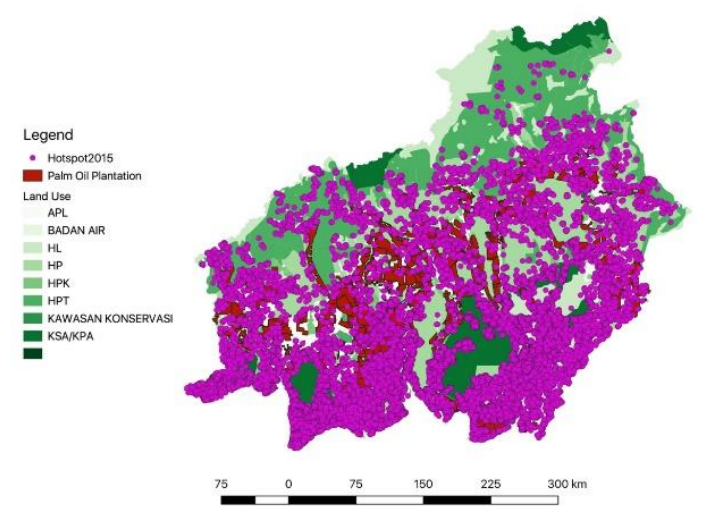

Figure 5. Hotspot occurrence in Central Kalimantan in 2015.

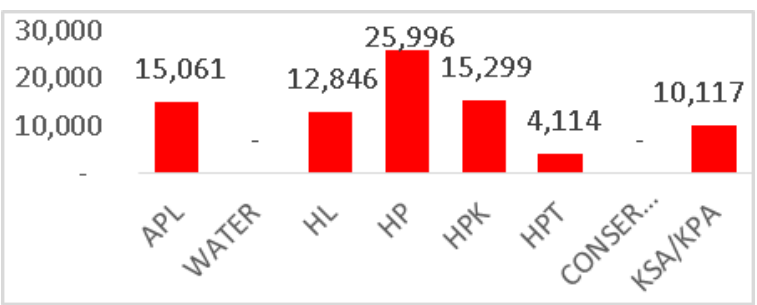

Figure 6. Dis tribution of hotspot based on land use

\section{Conclusion}

The hotspot does not mean the area is on fire; therefore, hotspot detection must be proven directly in the field. To create a mitigation effort on fires, the pinpoint of hotspot needs to be examined through the geographic information system by overlaying the hotspot area and the land-use area. The hotspots in the area of palm oil company must be ascertained first, whether they are on productive land such as in the planted area or in the bushes. The evaluation of the IUP (Ijin Usaha Perkebunan) area is essential because it is vast, and not every meter square is used as a cultivation area. Therefore, the coordination among agencies is needed in particular coordination of forestry agency and the district Estate Crop Agency needs to clarify and ensure the detected hotspot. By regulation, the authority responsible for fostering the concession is the District Estate Crop Agency. On a provincial level, the Governor Regulation relating to sanctions on companies whose land is proven to be the source of fire makes the province has a legal basis to conduct legal action towards companies to mitigate the prolonged fire.

This study suggested that risk mapping is vital for fire management to mitigate the spread of fire. The region to be fire-prone within the palm oil cultivation is suggested to form a preventive act through active forestfires monitoring. In sum, this study is expected to provide a map of forest fires' risk around the cultivation area, mainly palm oil plantation, and help the fire authorities as well as stakeholders to identify the risk zone for fires prevention in the future. 


\section{References}

1. World Resources Institute. The State of Forest: Indonesia, Forest Watch Indonesia, and Washington DC: Global Forest Watch, ISBN 1-56973-492-5 (2002)

2. D. Fuller, TC. Jessup, and A. Salim. Loss of forest cover in Kalimantan, Indonesia since the 1997-1998 El Nĩno, Conserv. Biol., 18, 249-254. (2004)

3. CV. Barber and J. Schweithelm. Trial by fire. Forest fires and forestry policy in Indonesia's era of cris is and reform, World Resources Institute (WRI), Forest Frontiers Initiative, in collaboration with WWF-Indonesia and Telapak Indonesia Foundation, Washington DC. (2000).

4. DLA. Gaveau et al. Major atmospheric emissions from peat fires in Southeast Asia during nondrought years: Evidence from the 2013 Sumatran fires. (2014)

5. JG. Goldammer, W. Schindele, B. Siebert, AJ. Hoffman, and H. Abberger. Impacts of fire on dipterocarp forest ecosystems in Southeast Asia. (1999)

6. AA. Hoffmann, A. Hinrichs, and F. Siegert. Fire Damage in East Kalimantan in 1997/98 Related to Land Use and Vegetation Classes: Satellite Radar Inventory Results and Proposal for Further Actions. (1999)

7. X. Pan, M. Chin, CM. Ichoku and R. Field. Connecting Indonesian Fires and Drought with the Type of El Niño and Phase of the Indian Ocean Dipole During 1979-2016. Journal of Geophysical Research: Atmospheres. (2018)

8. CC. Chen, HW. Lin, JY. Yu, and MH. Lo. The 2015 Borneo fires: What have we learned from the 1997 and 2006 El Niños? https://doi.org/10.1088/1748-9326/11/10/104003 (2016)

9. F. Ramdani and M. Hino. Land Use Changes and GHG Emissions from Tropical Forest Conversion by Oil Palm Plantations in Riau Province, Indonesia. PLoS ONE \& (7): e70323. (2013) 